\title{
Examination of the preservice chemistry teachers' understanding of periodic table concepts
}

\author{
Şenol Şen ${ }^{1, *}$ \\ ${ }^{1}$ Hacettepe University, Faculty of Education, 06800, Beytepe, Ankara, Turkey
}

\begin{abstract}
The purpose of this study was to examine the preservice chemistry teachers' understanding of periodic table concepts and some atomic properties. The study group of this study was comprised of 17 preservice chemistry teachers who were undergraduate students at a public University. The preservice teachers' ages are between 19 and 26, and the mean is $21.12(\mathrm{SD}=1.83)$. In addition, the 14 of the preservice teachers are female and three are male. In the study, concept maps and lotus blossom technique were used as data collection tools in order to determine the understanding of preservice chemistry teachers about the periodic table concepts. Data obtained through these techniques was analysed to figure out the useful of these assessment tools. The results of the analysis indicated that preservice teachers have limited understanding of the periodic table and its properties. In addition, at the end of the study, it was determined that they have many misunderstanding.
\end{abstract}

\section{Introduction}

Studies on chemistry education aim to reveal the way students learn and construct the concepts of chemistry, their applications and thinking styles; the difficulties they have in learning processes and the problems they encounter. In addition to that, developing effective approaches of teaching to cope with the difficulties in the learning process is also among the areas of research for chemistry education researchers [1] Most of the research on chemistry education available in the literature focusses on the way students understand the concepts of chemistry $[2,3]$. A review of those studies has made it clear that many students have misconceptions in this respect $[4,5,6]$. Periodic table, one of the basic subjects of chemistry, plays important roles in understanding chemical elements [7]. Several studies have emphasized the importance of periodic table $[7,8,9,10]$.

Periodic table is a cornerstone in learning chemistry and it is an instrument helping to organise whole chemistry [11]. It would be more rational to know the typical members of the eight main groups and their properties instead of learning the properties of more than one hundred elements in the periodic table separately. For instance, students who know the properties of noble gases, transition metals and of rare earth elements can make guesses

* Corresponding author: schenolschen@gmail.com 
about such physical and chemical properties of the elements in those groups as melting point, freezing point and electron configuration [11].

\subsection{Purpose of the study}

The main objective of studies concerning science education is to improve science teaching and learning. Chemistry teachers, who are to benefit from research results, can learn about the difficulties students have in understanding the concepts of chemistry. One of the concepts students mostly learn incorrectly and generally try to memorize is periodic table. However, the periodic table has an important and central role in understanding of chemical and physical properties of chemical elements. It was initially a list of elements consisting of increasing atomic masses. However, in time, it became a complex table of many different chemical and physical properties of the elements (such as melting point, boiling point, chemical bonding, atomic radius, ionization energy, intermolecular forces isotopes and allotropes). For this reason, it is expected that there will be difficulties in understanding of these concepts [10]. Some studies available in the literature report that the main problem students trying to learn chemistry have is students' failure to learn the basic concepts [12, $13,14]$. From this point on, the purpose of this study is to examine the preservice chemistry teachers' understanding of periodic table concepts and some atomic properties. Besides, standardized tests are limited in revealing students' understanding due to the complex nature of knowledge structure in chemistry [15]. Therefore, concept maps and lotus blossom technique have been used in determining pre-service teachers' understanding of periodic table.

\section{Method}

This study uses case study, which is one of qualitative study methods. In a case study, efforts are made to suggest results related to a certain case. Here, a case or several cases are investigated in-depth and factors related to the case (such as the setting, persons, event) are analysed in a holistic approach. Additionally, research on how the factors influence the case and how they are influenced by the case is also performed [16].

\subsection{Process}

Before the data collection process, preservice teachers were informed about the concept map and lotus blossom technique. The end of the term, preservice chemistry teachers were requested to construct their own concept maps related to these concepts such as periodic table, group, period, elements, atomic numbers, metals, non-metals, noble gases, atomic radius, ionization energy, electron affinity. In this way, the interrelationships among these concepts were determined. At the same time, the preservice teachers prepared their lotus blossoms.

\subsection{Study group}

The study group of this study was comprised of 17 preservice chemistry teachers who are undergraduate students at the Department of Mathematics and Science Education of a public University in the spring term of 2017-2018 academic year. The preservice teachers' ages are between 19 and 26, and the mean is 21.12 the standard deviation is 1.83 . In addition, the 14 of the preservice teachers are female and three are male (Table 1). The study is conducted in a Chemistry course that included the concepts related to periodic table and properties of elements in periodic table. 
Table 1. Preservice chemistry teachers' characteristics

\begin{tabular}{|c|c|c|c|}
\hline Variables & \multicolumn{3}{|c|}{ f } \\
\hline Age & \multicolumn{3}{|c|}{$19-26($ Mean $=21.12, \mathrm{SD}=1.83)$} \\
\hline \multirow{2}{*}{ Gender } & \multicolumn{2}{|c|}{ Female } & Male \\
\hline & \multicolumn{2}{|c|}{14} & 3 \\
\hline \multirow{3}{*}{ Grade point average } & \multicolumn{2}{|c|}{ Female } & Male \\
\hline & \multicolumn{2}{|c|}{2.66} & 1.97 \\
\hline & \multicolumn{3}{|c|}{$2.54(\mathrm{SD}=.56)($ Overall $)$} \\
\hline \multirow{2}{*}{ Class } & 2nd & 3rd & 4th \\
\hline & 14 & 2 & 1 \\
\hline
\end{tabular}

\subsection{Data collection tools}

In the study, concept maps and lotus blossom technique were used as data collection tools in order to determine the understanding of preservice chemistry teachers about periodic table. Concept maps were developed by Novak et al on the basis of Ausubel's "meaningful learning" [17]. Concept maps are pictures showing how an individual associates the key concepts related to a subject in his mind [18]. They can be used as an effective instrument to uncover learners' conceptual frameworks [19]. In this study, the method of concept mapping from scratch is used. The concept maps can use to as an assessment tool as an instructional tool to support learning [17]. However, in this study they were used to assess the preservice teachers' understanding and misunderstanding. Concept maps are the knowledge representation tools that generate new ideas, organize and represent the knowledge structures. Furthermore, they show that how learners integrate new knowledge into pre-existing knowledge and how relate al concepts in their minds.

The second data collection tool of this study is lotus blossom technique. Lotus Blossom Technique was produced from creative techniques developed in Japan [20]. The technique is based on the use of analytic skills and it helps to generate ideas to offer the best possible solution to the problem, which is considered. In the centre of lotus blossom diagram, there is a main (central) concept that was written by the researcher. There are eight boxes around the main concept, and each eight boxes have further eight different boxes. Firstly, students are asked to fill out the eight boxes around the main concept and then the other eight boxes of the each of eight boxes (Figure 1). After students write down 8 different thoughts or concepts about the central concept, they write down 8 new concepts again associated with those 8 concepts. They can also draw shapes or write down analogies, descriptions, explanations or examples instead of concepts. The central topic (theme) is divided into pieces and new ideas are generated to perform analyses in this technique [21].

\begin{tabular}{|c|c|c|c|c|c|c|c|c|}
\hline a1 & a2 & a3 & b1 & b2 & b3 & c1 & c2 & c3 \\
\hline a8 & A & a4 & b8 & B & b4 & c8 & C & c4 \\
\hline a7 & a6 & a5 & b7 & b6 & b5 & c7 & c6 & c5 \\
\hline h1 & h2 & h3 & A & B & C & d1 & d2 & d3 \\
\hline h8 & H & h4 & H & M & D & d8 & D & d4 \\
\hline h7 & h6 & h5 & G & F & E & d7 & d6 & d5 \\
\hline g1 & g2 & g3 & f1 & f2 & f3 & e1 & e2 & e3 \\
\hline g8 & G & g4 & f8 & F & f4 & e8 & E & e4 \\
\hline g7 & g6 & g5 & f7 & f6 & f5 & e7 & e6 & e5 \\
\hline
\end{tabular}

M: Main (central) concept

Fig. 1. The overall sheet of lotus blossom technique. 


\subsection{Data analysis}

The data collected through concepts maps and lotus blossom technique was put to content analysis. The concepts related to periodic table were determined in lotus blossom technique and thus the themes for the concepts were distinguished. The themes and concepts were tabulated. External auditor was consulted for help during the analyses, and the concepts and themes were analysed together.

Concept maps prepared by the pre-service teachers were also evaluated through holistic scoring- one of concept map scoring methods [22]. Then, the incomplete incorrect parts and errors appearing in students' proposals were detected. Member checking was made for the proposals determined by the researcher. Pre-service teachers' incomplete or incorrect concepts were determined in this way, and they were tabulated.

\section{Findings}

Concept maps and lotus blossom technique were used as the tools of data collection in determining pre-service teachers' understanding of periodic table concepts. The data collected through both instruments were analyzed by the researcher with the help of an external auditor and with exchange of views. While the data collected through lotus blossom technique indicated pre-service teachers' knowledge of periodic table, the data collected through concept maps demonstrated pre-service teachers' misconceptions. Lotus blossoms filled by the pre-service teachers were examined and the concepts most commonly used by the participants were shown in tables. The concepts they had determined for eight categories and the concepts they later used for the eight concepts were determined. As is clear from Table 2, the categories were divided into six subcategories as metals, nonmetals, noble gases, group and period. Six concepts were determined as the cut off point for the first eight concepts around the central concept and five concepts were determined as the cut off point for the concepts around eight concepts. Pre-service teachers wrote down other concepts in addition to such concepts as atom, atomic number, transition elements/ Group B elements, block, alkali metals, acids/bases, electronegativity, halogens, chemistry, chemical bonds, etc. for the eight central concepts as seen in the Table 2.

Table 2. Pre-service teachers' concepts about periodic table according to lotus blossom technique

\begin{tabular}{|c|c|c|c|c|c|c|c|}
\hline $\begin{array}{l}\text { Central } 8 \\
\text { Concepts } \\
\end{array}$ & f & Other Concepts & f & $\begin{array}{l}\text { Central } 8 \\
\text { Concepts } \\
\end{array}$ & f & Other Concepts & f \\
\hline \multirow{8}{*}{ Metal } & \multirow{8}{*}{16} & Alloying & 6 & \multirow{8}{*}{$\begin{array}{l}\text { Noble } \\
\text { Gases }\end{array}$} & \multirow{8}{*}{14} & $8 \mathrm{~A}$ & 6 \\
\hline & & Alkali Metal & 5 & & & Atomic structure & 10 \\
\hline & & Basic Oxide & 5 & & & $\begin{array}{l}\text { Chemical inertness/ } \\
\text { inability to form } \\
\text { chemical compounds }\end{array}$ & 7 \\
\hline & & $\begin{array}{c}\text { Conductors of heat } \\
\text { and electricity }\end{array}$ & 11 & & & $\begin{array}{c}\text { Low boiling and } \\
\text { melting points }\end{array}$ & 5 \\
\hline & & Cation & 6 & & & Gas & 6 \\
\hline & & Lustrous (shiny) & 10 & & & $\begin{array}{c}\text { Electron } \\
\text { configurations are } \\
\text { very difficult to alter }\end{array}$ & 11 \\
\hline & & Malleable and ductile & 9 & & & Oktet & 5 \\
\hline & & $\begin{array}{l}\text { The Alkaline } \\
\text { Earth Metal } \\
\end{array}$ & 5 & & & Nonreactive & 8 \\
\hline \multirow{4}{*}{ Nonmetal } & \multirow{4}{*}{15} & Anion & 6 & \multirow{4}{*}{ Group } & \multirow{4}{*}{13} & Alkali Metal & 8 \\
\hline & & $\begin{array}{l}\text { Nonconductors of } \\
\text { heat and electricity }\end{array}$ & 7 & & & Atomic radius & 6 \\
\hline & & $\begin{array}{l}\text { The most negative } \\
\text { electron affinities }\end{array}$ & 7 & & & $\begin{array}{c}\text { The number of } \\
\text { Valence electron }\end{array}$ & 6 \\
\hline & & Ionic Bond & 6 & & & Noble Gases & 7 \\
\hline
\end{tabular}




\begin{tabular}{|c|c|c|c|c|c|c|c|}
\hline & & Solid, liquid, or gas, & 5 & & & $\begin{array}{l}\text { The Alkaline } \\
\text { Earth Metal }\end{array}$ & 9 \\
\hline & & Brittle & 5 & \multirow{6}{*}{ Period } & \multirow{6}{*}{9} & Atomic radius & 9 \\
\hline & & Covalent Bond & 11 & & & Atomic number & 7 \\
\hline & & $\begin{array}{l}\text { Not lustrous (dull } \\
\text { appearance) }\end{array}$ & 10 & & & Electron affinity & 6 \\
\hline & & Molecular structure & 6 & & & Ionization energy & 5 \\
\hline \multirow{6}{*}{ Element } & \multirow{6}{*}{15} & Atomic Structure & 5 & & & Horizontal rows & 5 \\
\hline & & Same Type Atom & 11 & & & Orbital & 5 \\
\hline & & Metal & 7 & & & & \\
\hline & & Molecular structure & 8 & & & & \\
\hline & & Pure substance & 9 & & & & \\
\hline & & Chemical symbol & 8 & & & & \\
\hline
\end{tabular}

The proposals available in the concept maps prepared by the pre-service teachers were examined one by one and they are shown in Table 3. Thus, attempts were made to reveal the incomplete or incorrect concepts that the preservice teachers had.

Table 3. Incorrect or incomplete proposals available in pre-service teachers' concept maps

\begin{tabular}{|l|c|}
\hline \multicolumn{1}{|c|}{ Proposition } & f \\
\hline Of group elements, atomic radius increases from top to bottom. & 16 \\
\hline As moving from the left to the right along a period, atomic radius becomes smaller. & 17 \\
\hline Ionization energy increases from the left to the right in the same period. & 13 \\
\hline Ionization energy diminishes from top to bottom in the same group. & 13 \\
\hline Electron affinity increases from the left to the right in the same period. & 14 \\
\hline Electron affinity diminishes from top to bottom in the same group. & 14 \\
\hline Melting point rises as moving from the left to the right along a period. & 12 \\
\hline Electronegativity increases as atomic number increases. & 3 \\
\hline
\end{tabular}

\section{Conclusion and Discussion}

This study aimed to determine pre-service teachers' understanding of periodic table. For this purpose, 17 pre-service chemistry teachers attending a public university in Turkey were included in the research. Concept maps and lotus blossom technique were used as the tools of data collection so as to determine pre-service teachers' understanding of periodic table concepts. Lotus blossom technique was used rather in determining pre-service teachers' concepts about periodic table. Concept maps, on the other hand, were used in member checking in terms of pre-service teachers' incorrect or incomplete concepts.

On examining lotus blossoms prepared by pre-service teachers, it was found that the concepts most frequently written by pre-service teachers for the eight concepts in relation to the central concept were divided into six groups- namely, metals, non-metals, noble gases, group and period. An examination of the pre-service teachers' lotus blossoms demonstrated that pre-service teachers had misunderstandings. Since some of the concepts could be included due to the fact that cut off point was five and above, many incorrect concepts were not included in Table 2. Yet, the majority of the pre-service teachers said that noble gases could not form compounds, as seen in Table 2. However, it is known that some of the noble gases form compounds.

A large portion of the participants stated that atomic radius would increase as moving from top to bottom within a group. Although this knowledge is generally consistent with group members having small atomic numbers, it is not a really consistent proposal for group members having big atomic numbers. Increase in atomic radius is very little in bigger 
atoms. This is because inner-shell electrons in $\mathrm{d}$ and $\mathrm{f}$ orbitals in atoms with big atomic numbers are screened less than the outer-shell electrons when compared to $d$ and $f$ orbitals [23].

Another proposal made by the pre-service teachers was that atomic radius became smaller as moving from the left to the right along a period. However, this change in atomic radius is not very correct for transition elements because the radius of transition elements remain constant along a period- apart from a few deviations. In transition elements along a period, each electron added enters inner electron shell and is involved in screening outershell electrons against nucleus load [23].

The propositions saying, "ionization energy (IE) increases as moving from the left to the right in the same period" and "ionization energy (IE) diminishes from the top to the bottom in the same group" were detected in the concept maps. However, IE1 $<$ IE2 $<$ IE3 $<$ IE4 $<$ IE6 < IE5 < IE7 < IE8 relation is available between A group elements in the same period for the first ionization energies [23, 24]. Some of the pre-service teachers associated electronegativity with atomic number. Accordingly, they believed that electronegativity increased in parallel to the increase in atomic number. Electronegativity can be defined as an atom's ability to attract electrons from other atoms on which it is dependent. Thus, although fluorine's atomic number is not very big, it is the atom with the biggest electronegativity.

The participants did not include the proposals saying "electron affinity increases as moving from the left to the right in the same period" and "electron affinity diminishes as moving from top to bottom in the same group" in their concept maps. Electron affinity can be defined as enthalpy change during electron gain of an atom, which is in gas state. The pre-service teachers did not, for instance, say that some atoms such as noble gases did not tend to gain electrons. Although electron affinity diminishes as moving from top to bottom in the same group, the situation is different for the second period elements (for $\mathrm{N}, \mathrm{O}$ and $\mathrm{F}$ ) available in 5A, 6A and 7A groups. The electron affinity of the N, O and F elements which are in the second period is smaller than the one of $\mathrm{P}, \mathrm{S}$ and $\mathrm{Cl}$ elements in the third period $[23,24]$.

It was found that the pre-service teachers had the knowledge "melting point rises as moving from the left to the right along a period". Although the knowledge seems to be correct, it may not be said to be certainly correct. The pre-service teachers were found not to be aware of the fact that Si element in the third period had the highest melting point [23].

Consequently, in the present study, the concept maps and lotus blossoms technique were used as qualitative assessment tools of preservice teachers' understanding of some of the fundamental concepts of periodic table. Data obtained through these techniques was analysed to figure out the useful of these assessment tools. The results of the analysis indicated that preservice teachers have limited understanding of the periodic table and its properties. In addition, at the end of the study, it was determined that they have many misunderstanding. It was found that the pre-service teachers preferred memorizing the concepts related to periodic table. They said that a property would certainly increase or decrease as moving from top to bottom in a group and as moving from left to right in a period. It was also found in consequence of member checking that the pre-service teachers were not aware of exceptions and that they were not knowledgeable about this. Therefore, learners can probably learn some of the concepts by memorizing. Nevertheless, what is important is to determine whether they have learnt in depth. Thus, it would be beneficial to use differing techniques as instruments of measurement and evaluation. Concept maps and lotus blossom technique can be alternative instruments for measurement and evaluation. 


\section{References}

1. H. Tümay, Sci. Educ., 25, 21 (2016).

2. K. C. Trundle, R. K. Atwood, J. E. Christopher, Res. Sci. Teach, 39, 633 (2002).

3. M. Çalık, A. Ayas, J. Res. Sci. Teach., 42, 638 (2005).

4. R. Driver, J. Easley, Stud. Sci. Educ., 5, 61 (1978).

5. P. J. Garnett, D. F. J. Treagust, Res. Sci. Teach., 29, 121 (1992).

6. M. B. Nakhleh, J. Chem. Educ, 69, 191, (1992).

7. A. Brito, M.A. Rodríguez, M. Niaz, J. Res. Sci. Teach., 42, 84 (2005).

8. J. L. Marshall, J. Chem. Educ, 77, 979 (2000).

9. M. Niaz, M. Luiggi, Facilitating conceptual change in students' conceptual understanding of the periodic table. (Dordrecht: Springer, 2014).

10. H. J. Schmidt, T. Baumgärtner, H. J. Eybe, J. Res. Sci. Teach, 40, 257 (2003).

11. H. Demircioğlu, G. Demircioğlu, M. Çalık, Chem. Educ. Res. Pract, 10, 241 (2009).

12. M. M. Cooper, N. Grove, S. M. Underwood, M. W. Klymkowsky, J. Chem. Educ., 87, 869 (2010).

13. N. L. Burrows, S. R. Mooring, Chem. Educ. Res. Pract, 16, 5 (2015).

14. A. K. Griffiths A. K. A critical analysis and synthesis of research on students' chemistry misconceptions, in Schmidt, H. J. (ed.), Proceedings of the 1994 international symposium problem solving and misconceptions in chemistry and physics, ICASE (International Council of Associations for Science Education), 70 (1994).

15. K. S. Taber, Chemical misconceptions: Prevention, diagnosis and cure (Vol. I). (London: Royal Society of Chemistry, 2002).

16. A. Yıldırım, H. Şimşek, Sosyal Bilimlerde Nitel Araştırma Yöntemleri (8. Basım) [Qualitative Research Methods in Social Sciences ( ${ }^{\text {th }}$ Ed.)] (Ankara: Seçkin Yayıncılık, 2011).

17. J. D. Novak, D. B. Gowin, Learning how to learn. (New York: Cambridge University Press 1984).

18. M. A. Ruiz-Primo, S. E. Schultz, M. Li, R. J. Shavelson, J. Res. Sci. Teach, 38, 260 (2001).

19. J. J. Mintzes, J. H. Wandersee, J. D. Novak, Assessing science understanding: A human constructivist view. (San Diego, CA: Academic 2000).

20. T. L. Shen, J. C. Lai, EURASIA J. Math., Sci Tech. Ed, 14, 1509 (2018).

21. Ş. Şen, A. Y1lmaz, NFE-EJSME, 7, 144 (2013).

22. J. R. McClure, B. Sonak, H. K. J. Suen, .J. Res. Sci. Teach.,36, 475 (1999).

23. R. H. Petrucci, F. G. Herring, J. D. Madura, C. Bissonnette, General Chemistry: Principles and Modern Applications (10th ed.). (Toronto: Pearson Canada Inc, 2011).

24. R. Chang, K. A. Goldsby, Chemistry (12th Ed.). (New York, McGraw-Hill Education, 2016). 